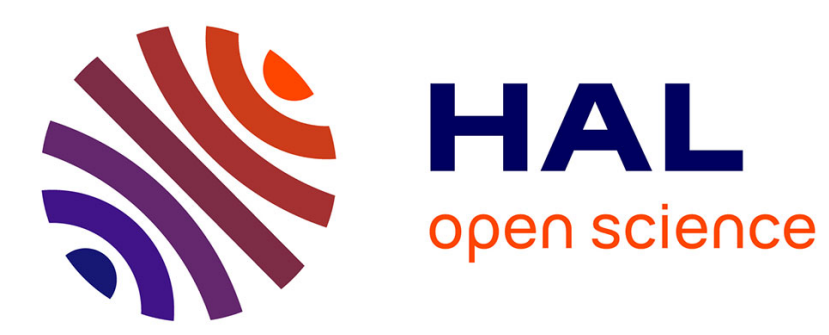

\title{
ELECTRONIC TRANSPORT IN LIQUID LITHIUM-LEAD ALLOYS
}

S. Wang, S. Lai

\section{To cite this version:}

S. Wang, S. Lai. ELECTRONIC TRANSPORT IN LIQUID LITHIUM-LEAD ALLOYS. Journal de Physique Colloques, 1980, 41 (C8), pp.C8-535-C8-539. 10.1051/jphyscol:19808135 . jpa-00220233

\section{HAL Id: jpa-00220233 https://hal.science/jpa-00220233}

Submitted on 1 Jan 1980

HAL is a multi-disciplinary open access archive for the deposit and dissemination of scientific research documents, whether they are published or not. The documents may come from teaching and research institutions in France or abroad, or from public or private research centers.
L'archive ouverte pluridisciplinaire HAL, est destinée au dépôt et à la diffusion de documents scientifiques de niveau recherche, publiés ou non, émanant des établissements d'enseignement et de recherche français ou étrangers, des laboratoires publics ou privés. 


\section{ELECTRONIC TRANSPORT IN LIQUID LITHIUM-L.EAD ALLOYS}

S. Wang and S.K. Lai

University of Waterioo, Waterzoo, Ontario, N2L 3GI, Canada

Abstract.- The self-consistent pseudopotential theory, developed previously for the binary alloys of simple metals, is applied to calculate (1) the excess electronic charges on the electronegative ions, i.e. $\mathrm{Pb}$ ions, due to the partial localization of the valence electrons on these ions and (2) the transport coefficients for the liquid Li-Pb alloy at different concentrations. It is found from this calculation that the partial localization of the valence electrons on the $\mathrm{Pb}$ ions in the Li- $\mathrm{Pb}$ alloy changes rapidly in going from the lowest concentration to the high concentration of $\mathrm{Pb}$ so that the transport coefficients of this alloy are strongly concentration dependent, as demonstrated in experiment. In addition, an improvement over the present type calculation is suggested.

\section{Introduction}

The energy independent model pseudopotential theory (Wang et al 1980, referred to as I hereafter) was rather successfully applied to the calculation of (i) the hard-sphere diameters, appearing in the Ashcroft-Langreth (AL) partial-structure factors (Ashcroft and Langreth 1967), and (ii) the electrical resistivity for the $\mathrm{Li}-\mathrm{Mg}, \mathrm{Li}-\mathrm{In}$ and $\mathrm{Li}-\mathrm{T} \ell$

alloys in the liquid state (Wang and Lai 1980, referred to as II hereafter). This paper presents the theoretical results of the extension of I and II to the liquid Li-Pb alloys.

2. Calculations

According to Wang and So (1977), within the pseudopotential theory the electrical resistivity $\rho$ in a liquid binary alloy can be written

$$
\begin{aligned}
& \rho=\left(<\mathrm{m}^{*}\left(\mathrm{k}_{\mathrm{F}}\right)>\left|\mathrm{N}_{\mathbf{k}_{\mathrm{F}}}\right|^{2}\right)^{2}\left(3 \pi \Omega /\left(4 \mathrm{k}_{\mathrm{F}}^{6}\right)\right) \\
& x \int_{0}^{2 k_{F}} d q q^{3}\left|<{\underset{\sim}{F}}_{F}+q\right|\left[w(\underset{\sim}{r})-w_{0}(\underset{\sim}{r})\right]\left|{\underset{\sim}{k}}_{F}>\right|^{2}
\end{aligned}
$$

where we used the usual atomic unit system. Herein $<\mathrm{m}^{*}\left(\mathrm{k}_{\mathrm{F}}\right)>$ and $\mathrm{k}_{\mathrm{F}}$ are respectively the full densityof-states effective mass $\mathrm{m}^{*}\left(\mathrm{k}_{\mathrm{F}}\right)$ and the Fermi wavevector $\mathrm{k}_{\mathrm{F}}$, averaged over the Fermi surface of the

(1) The number of the subject class is 7

(2) S. Wang, Department of Physics, University of Waterloo, Waterloo, Ontario, N2L 3G1, Canada alloy in which no electrical resistivity is pre-

sent. $\mathrm{N}_{\mathrm{k}_{\mathrm{F}}}$ is a re-normalization constant of the pseudo-wave-function (cf. equation (2.27) of $I$ ). $\Omega$ is the volume of the alloy and is usually written as ${ }^{N} \Omega_{0}, N$ and $\Omega_{0}$ being respectively the number of ions and the atomic volume. In equation $(1), W(\underset{\sim}{r})-W_{0}(\underset{\sim}{r})$ is a pseudo scattering potential and hence the scattering matrix element in this equation can be converted to

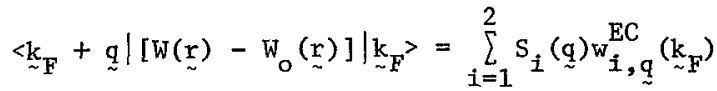
$-\sum_{i=1}^{2} s_{i}^{(0)}(\underset{\sim}{q}) w_{i, q}^{E C}\left(k_{\sim F}\right)$ where $w_{i, q}^{E C}\left(k_{\sim F}\right)$ is the form factor for the ith component of the alloy and $\mathrm{S}_{\mathrm{I}}(\underset{\sim}{\mathrm{q}})=\mathrm{N}^{-1}$

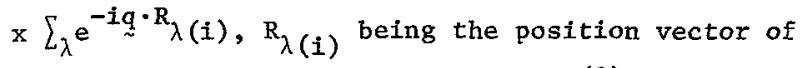
the $\lambda$ th ion of the $i$ th component. $s_{i}^{(0)}(q)$ is $s_{i}(q)$ with the ionic position vector ${\underset{\sim}{\lambda(i)}}_{\lambda(\text { replaced by }}$ the position vector of the same lon at its equilibrium position and is non-zero only if $q$ is a reciprocal lattice vector. Accordingly, the matrix element of $W_{0}(r)$ does not contribute to $p$ for the alloys of alkali metals, because all the non-vanishing reciprocal lattice vectors are not in the region of the q-integration for these alloys. This would lead to the expression used in $I$ for $\rho, 1 . e$. , 
$\rho=\left(\left\langle\mathrm{m}^{*} \underset{\sim \mathrm{F}}{\left.\mathrm{k}_{\mathrm{F}}\right)}\right\rangle\left|\mathrm{N}_{\mathrm{k}_{\mathrm{F}}}\right|^{2}\right)^{2} \rho_{\mathrm{f}}$

where $\rho_{f}$ stands for $\rho$ within the usual nearly-freeelectron (NFE) theory (cf. equation (3.4) of I). However, for the alloys for which the non-vanishing reciprocal lattice vectors are in the region of the q-integration, as given in equation ( 1 , the matrix element of $W_{0}(\underset{\sim}{r})$ would contribute to $\rho$. In reality, the structure of an alloy is too complex to determine accurately the non-vanishing reciprocal

lattice vectors for use in the calculation of $\rho$, given by equation (1). To find an approximation to this, it is worth noting from Wang and So (1977) that in equation (1), if $\left\langle\mathrm{m}^{*}\left(\mathrm{k}_{\sim}\right)\right\rangle$ is approximated by the first-order density-of-states effective mass, denoted by $\mathrm{m}^{*}\left(\mathrm{k}_{\mathrm{F}}\right)$, then $\mathrm{w}_{\mathrm{o}}(\mathrm{r})$ does not appear and $\rho$ becomes

$\rho=\left(\mathrm{m}^{*}\left(\mathrm{k}_{\mathrm{F}}\right)\left|\mathrm{N}_{\mathrm{k}_{\mathrm{F}}}\right|^{2}\right)^{2} \rho_{\mathrm{f}}$

This equation was rather successfully applied to the calculation of $\rho$ for the pure polyvalent metals in

II. Accordingly, for a binary alloy, consisting of an alkali metal and a polyvalent metal, $\rho$ may be written from equations (3) and (4) as

$\rho=\left(m_{c}^{*}\left(k_{F}\right)\left|N_{k_{F}}\right|^{2}\right)^{2} \rho_{f}$

where $m_{c}^{*}\left(k_{F}\right)$ stands for the electron density-ofstates effective mass of the alloy at the concentration $C$ and approaches the full density-ofstates effective mass from $\mathrm{m}^{*}\left(\mathrm{k}_{\mathrm{F}}\right)$ in going from the high concentration to a low concentration of the polyvalent metal.

\subsection{Input data}

In applying equation (5) to the calculation of $\rho$ for the binary alloys of interest here, we need to know the AL partial-structure factors of these alloys. As for this, we have followed II to determine these factors. The values, appearing in the present1y determined structure factors, for (i) the hard-sphere diameters, $\sigma_{1}$, (ii) the partial packing-densities, $\eta_{i}$, and (iii) the atomic volume,
$\Omega_{0}$, are summarized in table 1 .

As for the other input data, such as the Table 1. Values of $\Omega_{0}, \sigma_{i}$ and $\eta_{i}$ of $\mathrm{Li}-\mathrm{Pb}$ alloys at $800^{\circ} \mathrm{C} . \quad \mathrm{C}_{\mathrm{Pb}}$ stands for the concentration of the $\mathrm{Pb}$ component. $\mathrm{All}$ are in atomic units.

\begin{tabular}{cccccc}
\hline$c_{\mathrm{Pb}}$ & $\Omega_{0}$ & $\sigma_{1}$ & $\sigma_{2}$ & $\eta_{1}$ & $\eta_{2}$ \\
\hline 0.0 & 170.2 & 4.76 & - & 0.332 & - \\
0.1 & 165.3 & 4.37 & 4.71 & 0.026 & 0.298 \\
0.2 & 152.4 & 4.41 & 4.62 & 0.059 & 0.271 \\
0.4 & 183.6 & 4.53 & 4.58 & 0.106 & 0.165 \\
0.6 & 201.8 & 4.52 & 4.66 & 0.096 & 0.158 \\
0.8 & 217.0 & 4.45 & 4.79 & 0.042 & 0.213 \\
1.0 & 231.3 & - & 4.93 & - & 0.272
\end{tabular}

values of $\mathrm{N}_{\mathrm{k}_{\mathrm{F}}}, \mathrm{m}^{*}\left(\mathrm{k}_{\mathrm{F}}\right)$ and of the quantities appearing in $\rho_{f}$, they can be calculated as in $I$. Among the input data thus calculated yalues for $\mathrm{N}_{\mathrm{k}_{\mathrm{F}}}, \mathrm{m}^{*}\left(\mathrm{k}_{\mathrm{F}}\right)$ and $\mathrm{z}_{\mathrm{Pb}}^{*}=\mathrm{z}_{\mathrm{Pb}}-\rho_{\mathrm{Pb}, \mathrm{d}}$, being the effective valence charges of $\mathrm{a} \mathrm{Pb}$ ion in the alloy (see I for details), are summarized in table 2.

Table 2. Theoretical values of $\left|\mathrm{N}_{\mathrm{k}_{\mathrm{F}}}\right|, \mathrm{z}_{\mathrm{Pb}}^{*}, \mathrm{~m}^{*}\left(\mathrm{k}_{\mathrm{F}}\right)$, $\left\langle\mathrm{m}^{*}\left(\mathrm{k}_{\mathrm{F}}\right)>\right.$ and of $\mathrm{m}_{\mathrm{C}}^{*}\left(\mathrm{k}_{\mathrm{F}}\right)$ for $\mathrm{Li}-\mathrm{Pb}$ alloys at $800^{\circ} \mathrm{C}$. All are in atomic units.

$$
c_{\mathrm{Pb}} \mid \mathrm{N}_{\left.\mathrm{k}_{\mathrm{F}}\right|^{-2}} \mathrm{z}_{\mathrm{Pb}}^{*} \quad \mathrm{~m}^{*}\left(\mathrm{k}_{\mathrm{F}}\right)<\mathrm{m}^{*}\left(\mathrm{k}_{\mathrm{F}}\right)>\mathrm{m}_{\mathrm{C}}^{*}\left(\mathrm{k}_{\mathrm{F}}\right)
$$

$\begin{array}{llllll}0.0 & 0.97 & - & 1.14 & 1.15 & 1.15 \\ 0.1 & 0.94 & 4.61 & 1.09 & 1.14 & 1.14 \\ 0.2 & 0.91 & 4.82 & 1.04 & 1.28 & 1.28 \\ 0.4 & 0.87 & 4.91 & 0.95 & 1.09 & 1.02 \\ 0.6 & 0.84 & 5.02 & 0.89 & 1.06 & 0.91 \\ 0.8 & 0.83 & 5.13 & 0.84 & 1.03 & 0.84 \\ 1.0 & 0.81 & 5.21 . & 0.80 & 1.00 & 0.80\end{array}$

From the calculated $z_{\mathrm{Pb}}^{*}$ the probability that a valence electron is localized around an electronegative ion (i.e., $\mathrm{Pb}$ ), denoted by $\mathrm{f}\left(\mathrm{C}_{\mathrm{Pb}}\right)$, is 
calculated as in II, by using the equation, $f\left(c_{\mathrm{Pb}}\right)=C_{\mathrm{Pb}} \Delta \mathrm{z}_{\mathrm{Pb}}^{*} /\left(\mathrm{C}_{\mathrm{Pb}}{ }_{\mathrm{Pb}}+\mathrm{C}_{\mathrm{Li}}{ }^{\mathrm{L}_{\mathrm{Li}}}\right)$. Here $\Delta \mathrm{z}_{\mathrm{Pb}}^{*}$ is the change in $\mathrm{z}_{\mathrm{Pb}}^{*}$ in going from the pure $\mathrm{Pb}$ metal to the $\mathrm{Li}-\mathrm{Pb}$ alloy of concentration $\mathrm{C}_{\mathrm{Pb}}$ and represents the valence-electron charges localized on a $\mathrm{Pb}$ ion from I and II. The calculated $f\left(\mathrm{C}_{\mathrm{Pb}}\right)$ is displayed and compared with those from II for the Li-Mg and Li-In alloys in figure 1. Also, we list in table 2 the values of $\left\langle\mathrm{m}^{*}(\underset{\sim}{\mathrm{F}})\right\rangle$, calculated from $\mathrm{C}_{\mathrm{Li}}\left\langle\mathrm{m}^{*}\left(\underset{\sim \mathrm{F}}{\left.\left.\mathrm{k}_{\mathrm{F}}\right)\right\rangle_{\mathrm{Li}}}+\mathrm{C}_{\mathrm{Pb}}\left\langle\mathrm{mn}{ }^{*}\left(\underset{\sim \mathrm{F}}{\mathrm{k}_{\mathrm{F}}}\right)\right\rangle_{\mathrm{Pb}}\right.\right.$ using (i) $\left\langle\mathrm{m}^{*}\left({\underset{\sim F}{\mathrm{~F}}}_{\mathrm{k}}\right)\right\rangle_{\mathrm{Pb}}$ $=1$ au (Kittel 1968) and (ii) $\left\langle\mathrm{m}^{*}\left(\mathrm{k}_{\mathrm{F}}\right)\right\rangle_{\mathrm{Li}}=1.35$ au at $\mathrm{C}_{\mathrm{Pb}}=0.2$ (for which $\Omega_{\mathrm{o}}$ is smaller than the atomic volume of Li at its melting point) and 1.15 au for the other $\mathrm{C}_{\mathrm{Pb}}$. It should be noted that the present choice of the values for $\left\langle\mathrm{m}^{*}\left(\mathrm{k}_{\mathrm{F}}\right)\right\rangle_{\mathrm{Li}}$ can be justified from the work of Ham (1962) and that of So et al (1977). We also note that the values of $\left\langle\mathrm{m}^{*}\left(\underset{\sim F}{\mathrm{k}_{\mathrm{F}}}\right)\right\rangle$ in table 2 do not include the enhance due to the electronic partial localization, as characterized by the present calculated $f\left(\mathrm{C}_{\mathrm{Pb}}\right)$.

\subsection{Electrical resistivities}

In view of the fact that equation (5) with $m_{c}^{*}\left(k_{F}\right)$ equal to $m^{*}\left(k_{F}\right)$, $1 . e$. , equation (4), was rather successfully applied to the calculation of $\rho$ for the liquid Li-Mg, Li-In and Li-Tl alloys in II, we first applied equation (4), as described above, to the calculation of $\rho$ for the $\mathrm{Li}-\mathrm{Pb}$ alloys. The calculated results are shown also in figure 1 along with the experimental values (Nguyen and Enderby 1977, Van Der Marel et al 1978).

From the comparison of the theoretical and experimental results, it is seen that equation (4) is a very poor approximation to equation (1) for $\mathrm{C}_{\mathrm{Pb}}$ between 0.1 and 0.3 . This is because, in going from $\mathrm{C}_{\mathrm{Pb}}=0.4$ to $\mathrm{C}_{\mathrm{Pb}}=0.2$, the contribution from $\mathrm{W}_{\mathrm{o}}(\underset{\sim}{(r)}$ becomes significantly smaller, whereas $\left\langle\mathrm{m}^{*}\left(\mathrm{k}_{\mathrm{F}}\right)\right\rangle$ becomes much larger due to a large contraction of the atomic volume (cf. $\Omega_{0}$ and $\left\langle\mathrm{m}^{*}(\underset{\sim \mathrm{F}}{\mathrm{k}})\right\rangle$ in tables). This

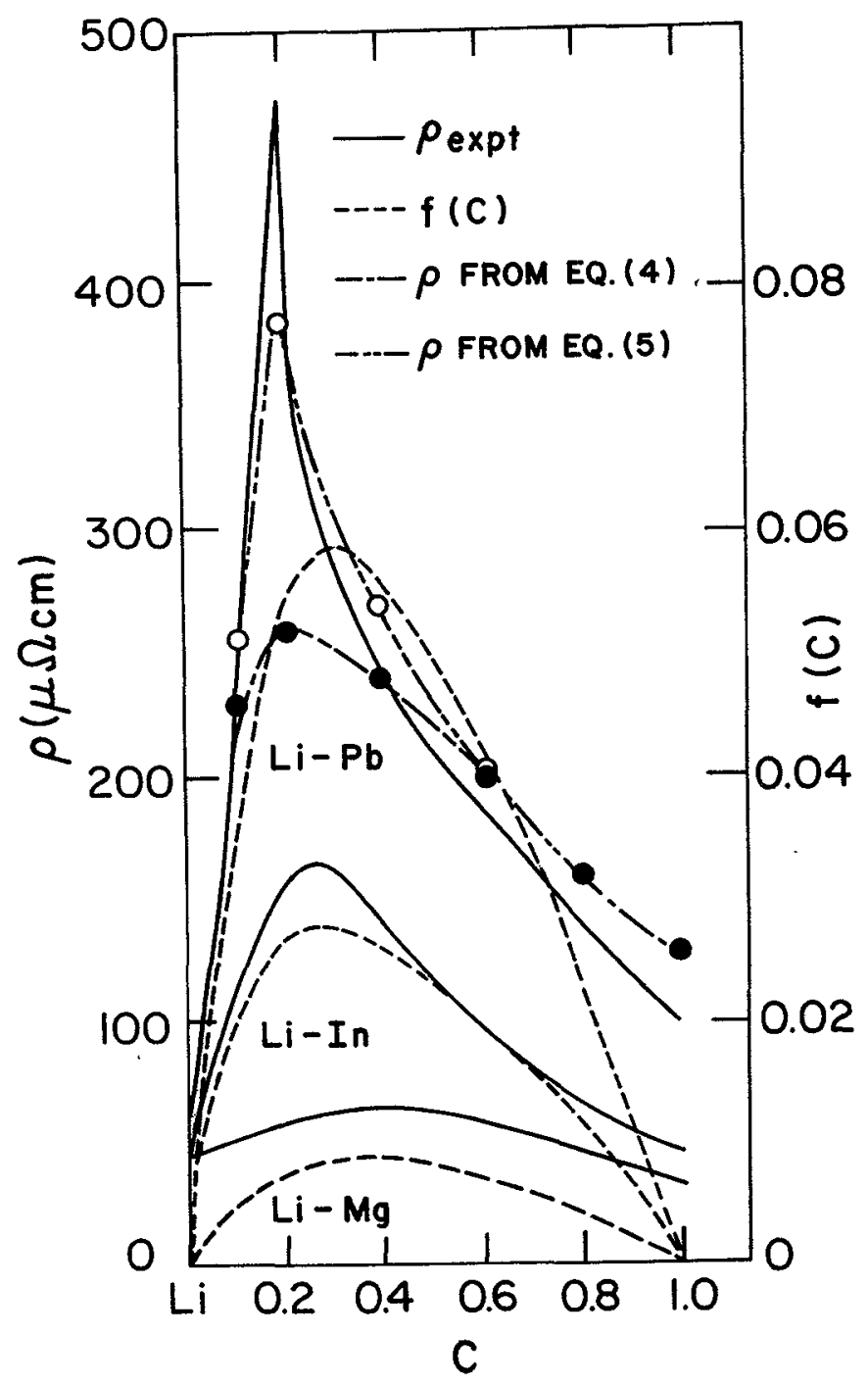

Figure 1. Various $\rho$ and $f(c)$ for Li-based alloys.

does not occur in the Li-based alloys considered in II. It thus appears that equation (3) is more appropriate than equation (4), which turns out to be applicable only for $08 \leq \mathrm{C}_{\mathrm{Pb}} \leq 1$ in the case of $\mathrm{Li}-\mathrm{Pb}$, for $0 \leq \mathrm{C}_{\mathrm{Pb}} \leq 0.2$. Then, $\rho$ for $0.2<\mathrm{C}_{\mathrm{Pb}}<0.8$ in the case of $\mathrm{Li}-\mathrm{Pb}$ may be calculated by using equation (5) with $\mathrm{m}_{\mathrm{c}}^{*}\left(\mathrm{k}_{\mathrm{F}}\right)$ between the corresponding $\mathrm{m}^{*}\left(\mathrm{k}_{\mathrm{F}}\right)$ and $\left\langle\mathrm{m}^{*}\left(\mathrm{k}_{\mathrm{F}}\right)\right\rangle$. The values of $m_{c}^{*}\left(k_{F}\right)$ so estimated are also listed in table 2. The corresponding calculated $\rho$, 1.e., $\rho$ calculated using equation (5) with $\mathrm{m}_{\mathrm{c}}^{*}\left(\mathrm{k}_{\mathrm{F}}\right)$ given in table 2, is also displayed in figure 1 . The corresponding thermoelectric power $\mathrm{Q}\left(\mathrm{C}_{\mathrm{Pb}}\right)$, calcu- 
lated using equation (3.5) without $\zeta$ in I, i.e., the usual NFE formula, is shown in figure 2 along with the experimental Q (Nguyen and Enderby 1977). We note that the omission of $\zeta$ is not serious, because the two terms making up $\zeta$ cancel to a large extent in the case of $\mathrm{Li}-\mathrm{Pb}$.

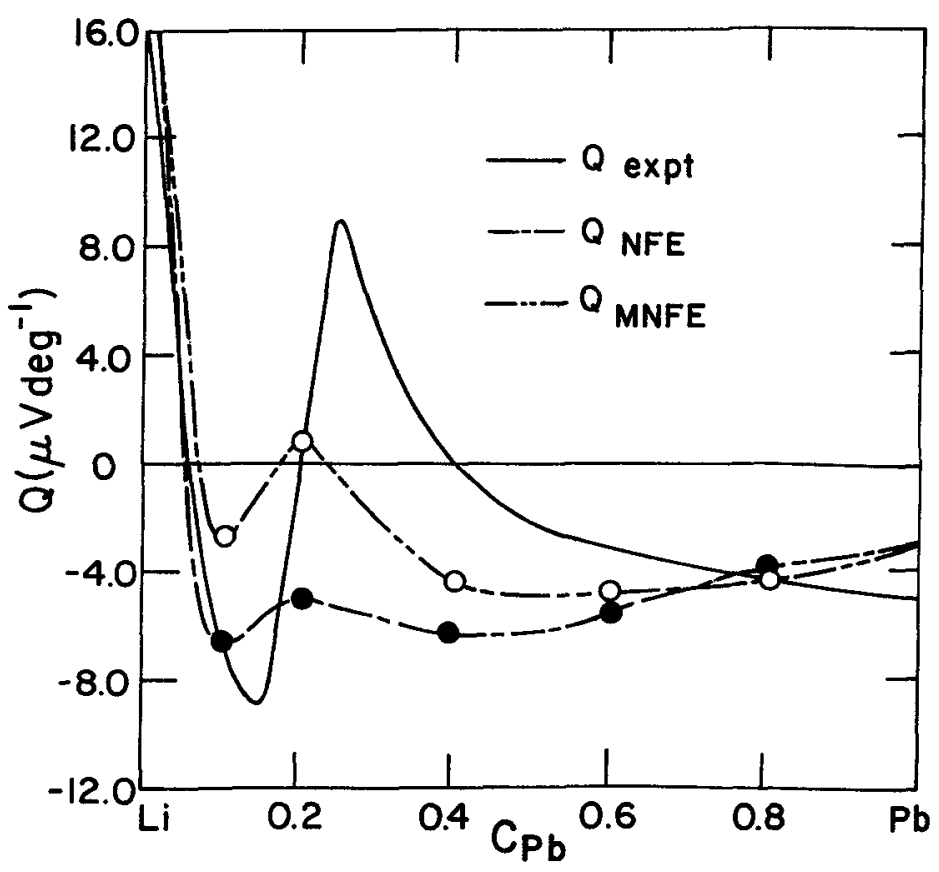

Figure 2. Various $Q$ for $\mathrm{Li}-\mathrm{Pb}$ at $\mathrm{T}=800^{\circ} \mathrm{C}$

\section{Discussion}

We have used our theoretically determined partial-structure factors to calculate the intensity of coherently scattered neutrons for $\mathrm{Li}-\mathrm{Pb}$ alloys as in Bhatia and Ratti (1976). The agreement between the calculated result and the experimental value (Ruppersberg and Egger 1975) becomes worse in going from the high concentration to a low concentration of $\mathrm{Pb}$. In view of this, we have repeated the calculation of $\rho$ with the AL partialstructure factors replaced by those of Bhatia and Ratti, which include the effects of the compounds of $\mathrm{LI}$ and $\mathrm{Pb}$ atoms and produce quite accurately the intensity of scattered neutrons for the Li-Pb alloy at $\mathrm{C}_{\mathrm{Pb}} \cong 0.2$. However, the results of the calcu- lated $p$ are about the same as those in figure 1 , because a cancellation between terms in $\rho_{f}$ in equation (5). In passing, we note that the BhatiaRatti structure factors may not be theoretically more appropriate than those of AL for electronic transports in the liquid $\mathrm{Li}-\mathrm{Pb}$ alloys. This is because the compounds of the $\mathrm{Li}$ and $\mathrm{Pb}$ atoms are normally not so stable and may become unstable in electronic transport. This speculation is really supported rather strongly by our calculation in this work for the thermoelectric power, which is too dependent upon the partial-structure factors at $q=2 k_{F}$.

We now turn to the discussion of the app1icability of the NFE theory for the Li-Pb alloys. $f(C)$ is generally significantly greater for $L i-P b$ than for the Li-Mg and Li-In alloys (see figure 1) and the use of the NFE theory, as described above, for the Li-Pb alloy at $\mathrm{C}_{\mathrm{Pb}}$ between 0.2 and 0.6 is not guaranteed. This prompts us to modify the NFE theory regarding the $\mathrm{Li}-\mathrm{Pb}$ alloy as a system consisting of (i) the $\mathrm{Li}$ ions with $Z_{\mathrm{Li}}$ unchanged, i.e., unity, (ii) the $\mathrm{Pb}$ ions with $\mathrm{Z}_{\mathrm{Pb}}=4-\Delta$ (rather than 4, which is the usual value for the valence charge of $\mathrm{a} \mathrm{Pb}$ ion and is used in the NFE theory), $\Delta$ being the valence-electron charges localized on a $\mathrm{Pb}$ ion and (iii) $\mathrm{n}\left(1-\mathrm{f}\left(\mathrm{C}_{\mathrm{Pb}}\right)\right)_{\text {nearly }}$ free electrons rather than $n$, $n$ being the number density of valence electrons (the details will be described in a coming paper $)$. These $n\left(1-f\left(C_{P b}\right)\right)$ nearly free electrons are the actual carriers in the electronic transport and $\rho$ can be written as that given by equation (5) with (i) $\mathrm{z}_{\mathrm{Pb}}$ replaced by $4-\Delta\left(\right.$ which is $\Delta \mathrm{z}_{\mathrm{Pb}}^{*}$ given above in the present calculation and (ii) $n$ replaced by $n\left(1-f\left(c_{p b}\right)\right)$ in the determination of $k_{F}$, appearing in $\rho_{f}$. Apparent1y, $\rho$ thus obtained is theoretically more appropriate than that as given by equation (5). 
Nevertheless, the values of $\rho$, calculated using the modified NFE (MNFE) theory, are found to be about the same as those in figure 1 . It is worth noting that the method, used here for calculating $\Delta \mathrm{Z}_{\mathrm{Pb}}^{*}$, was derived in $\mathrm{I}$ for the valence electrons with $f(C) \leq 0.02$ and may not be applicable for the valence electrons in the $\mathrm{Li}-\mathrm{Pb}$ alloy at $\mathrm{C}_{\mathrm{Pb}}$ between 0.2 and 0.6 , because $f(C)$ for the latter electrons is considerably greater than 0.02 . It thus seems to us that the actual valence-electron charges localized on a $\mathrm{Pb}$ ion is larger than our calculated value for $0.2 \leq \mathrm{C}_{\mathrm{Pb}} \leq 0.6$. In view of this, to see if we can produce positive $\mathrm{Q}\left(\mathrm{C}_{\mathrm{Pb}}\right)$ as experimenta11y observed for $\mathrm{C}_{\mathrm{Pb}}$ between 0.2 and 0.4 , we set $\Delta$ equal to $\Delta \mathrm{z}_{\mathrm{Pb}}^{*}, 1.5 \Delta \mathrm{z}_{\mathrm{Pb}}^{*}, 1.3 \Delta \mathrm{z}_{\mathrm{Pb}}^{*}$, 1. $15 \Delta \mathrm{z}_{\mathrm{Pb}}^{*}$ and $\Delta \mathrm{z}_{\mathrm{Pb}}^{*}$ respectively for $\mathrm{C}_{\mathrm{Pb}}=0.1,0.2$, $0.4,0.6$ and 0.8 and re-calculated $\rho$ and $Q$ within the MNFE theory. The calculated $\rho$ is found to be not very much different from that obtained using equation (5) within the NFE theory and shown in figure 1. However, Q thus calculated differs significantly from that obtained in the NFE theory and is in better agreement with experiment in sign, as shown in figure 2. This would imply that the unusual nature of $\mathrm{Q}$ of the $\mathrm{Li}-\mathrm{Pb}$ alloy is primarily associated with the excess electronic charges on the $\mathrm{Pb}$ component due to the partial localization of the valence electrons on this component.

Finally, it is appropriate to discuss the effect of the valence-electron-spin-orbital interaction, which is important for the $\mathrm{Pb}$ atoms, on $\rho$. According to so et al (1978), the spin-orbital interaction enhances $\rho$ by about $7 \%$ for the pure $\mathrm{Pb}$ metal in the liquid state. In going from the $\mathrm{Pb}$ metal to the $\mathrm{Li}-\mathrm{Pb}$, the electron orbital angular momentum will be enhanced by its partial localization on $\mathrm{a} \mathrm{Pb}$ ion and $\rho$ would be increased significantly by the spin-orbital interaction at
$\mathrm{C}_{\mathrm{Pb}}$ in the vicinity of 0.2 . Accordingly, when the spin-orbital contribution is considered, $p$ at $\mathrm{C}_{\mathrm{Pb}}=0.2$ would be considerably greater than that, calculated by equation (5) and shown in figure 1. From this and the comparison of $\mathrm{f}(\mathrm{C})$ for $\mathrm{Li}-\mathrm{Pb}$ with that of $\mathrm{Li}-\mathrm{In}$ or $\mathrm{Li}-\mathrm{Mg}$ in figure 1 , we may conclude that the enhanced $\rho$ in the Li-Pb alloys is due to the partial localization of the valence electrons on the electronegative component, as in the $\mathrm{L}-\mathrm{i}-\mathrm{Mg}$ and Li-In alloys.

\section{Acknowledgment}

This work was supported in part by NSERC of Canada.

\section{References}

Ashcroft NW and Langreth DC 1967 Phys. Rev. 156

$685-92$

Bhatia $A B$ and Ratti VK 1976 J. Phys. F: Metal

Phys. $\underline{6}$ 927-41

Ham FS 1962 Phys. Rev. 128 2524-41

Kittel C 1968 Introduction to Solid State Physics

(New York: John Wiley)

Nguyen VT and Enderby JE 1977 Phf1. Mag. 35 1013-9 Ruppersberg H and Egger H 1975 J. Chem. Phys. 63

4095-103

So $\mathrm{CB}$, Moore RA and Wang S 1978 J. Phys. F: Metal

Phys. 8 785-97

So CB, Takegahara K and Wang S 1977 J. Phys. F:

Metal Phys. 7 1453-65

Van Der Marel $\mathcal{C}$, Brandenburg EP and Van Der Lugt $W$ 1978 J. Phys. F: Metal Phys. $\underline{8}$ L273-6

Wang S, Lai SK and So CB 1980 J. Phys. F : Metal

Phys. 10 445-59

Wang S and Lai SK 1980 J. Phys. F: Metal Phys. 10 vsept. issue

Wang S and So CB 1977 J. Phys. F: Metal Phys. $\underline{7}$ 1439-52 